\title{
IDENTIFYING IMPORTANT SKILLS SET TO SUPPORT REPORTING AND ANALYZING IN PROJECT MANAGEMENT
}

\author{
Iwona ZDONEK \\ Silesian University of Technology; iwona.zdonek@polsl.pl, ORCID: 0000-0002-3377-0904
}

Purpose: The article presents the results of qualitative research related to identifying the set of skills needed in project management business analysis.

Design/methodology/approach: To recognize the set of skills, it was important to focus on three pivotal issues, starting with specifying which layers of business analysis in project management can be extracted, then answering the question of which IT tools are to be used in this analysis as well, and which skills are needed to perform in it. The main research method was participation observation by way of the author's involvement in a project management team.

Findings: The following layers of business analysis in project management were established: 1) data management, 2) intelligent calculations, 3) delivery mode, 4) consumption device, 5) business enablement. The most important skills are as follows: joining disparate data sources, cleaning data, organizing data better, creating calculations, adjusting visualizations to the tools used by end-users to consume visualizations. MS Excel and MS Access were found to be valuable tools used in this analysis.

Originality/value: New in the paper is an examination of the set of skills needed in the project management business analysis in the context of applying MS Excel and MS Access.

Keywords: business intelligence, BI tools, BI skills.

Category of the paper: A case study.

\section{Introduction}

The technological capability to collect data has expanded faster than the ability to turn them into useful information. For this reason, we can observe the multiplicity of IT tools coming up in markets related to business analysis, which help turning data into valuable information. These tools are connected with the discipline called Business Intelligence (BI). Business intelligence (BI) is a term used to describe a broad category of applications, technologies, architectures, and processes for gathering, storing, accessing and analyzing operational data to provide business users with timely competitive information to enable better insights for 
operational and strategic decision-making (Negash, 2004; Watson, 2009). However, when it comes to using data to answer business questions, technology is only one part of the solution. Although there is a wealth of research about Business Intelligence technology (Bobriakov, 2018; Abbott, 2014; Green 2010), we can grasp fewer works on the human components and skills needed to be successful in developing BI solutions. Meanwhile, according to Todd, "BI skills and the best methods to teach those skills need to be further analyzed to improve data-driven decisions" (Todd, 2017). Furthermore, he emphasizes that "organizations have had limited success with user adoption in spite of new technology tool enhancements and large technology investment". Hence, one of the important metrics used to measure application success is user adoption. This leads us to BI skills, without which using application is impossible. In this regard, interest in BI education has begun to attract scholars' attention.

So far, researchers have focused on five areas related to BI education (Wang, 2015). Firstly, they investigated the current state of business intelligence education (e.g. Chiang et al., 2012; Davis, and Woratschek, 2015; Sircar, 2009; Wixom et al., 2011, 2014). Secondly, they explored the role of data-savvy professionals in practice (Wixom et al., 2014; Davenport, and Patil, 2012; Lee et al., 2014; Van der Aalst, 2014). Thirdly, they investigated the design and development of the BI curriculum (e.g. Al-Sakran, 2014; Chiang et al., 2012; Gorman, and Klimberg, 2014; Wilder, and Ozgur, 2015). Fourthly, they studied teaching cases and learning activities for BI (e.g. Edgington, 2011; Pomykalski, 2014; Presthus, and Bygstad, 2012). Finally, they investigated the skill set and knowledge domains of BI professionals (e.g. Chiang et al., 2012; Li et al., 2014; Hosack, and Sagers, 2015, Momonov et al., 2015, Wixom et al., 2014).

This article fits in the fifth area of previous research and it is focused on skills needed in business analysis in project management issues. When it comes to business analysis in project management, we can observe the high involvement of project resources in performing various types of analysis and reports. Moreover, special attention is paid to reporting processes, especially regarding cost reporting. In projects financed by the EU, many special requirements determine the execution of reports and analysis. For this reason, special IT systems and templates of documents for reports and analyses that are required in these systems are created. Usually, they are not compatible with the internal organization of the financial systems which must prepare reports, which makes it impossible to perform them automatically. This situation requires the presence of skills in the project team that enables the creation of required reports based on the huge amounts of data generated by internal accounting systems. The question that arises is which skills should be present to enable the creation of reports and analysis related to financial issues of project management? 
The main purpose of this article is to answer the question set above, which also implies finding answers to the following questions:

1. Can the layers of business analysis indicated in the literature be extracted in the analysis that is performed during project management?

2. Which IT tools are necessary for effective business analysis in project management?

3. Which BI skills are needed to enable conducting business analysis in project management?

This study is structured as follows. In the chapter foundation of reports and analysis creation, some contextual background for BI skills needed for reports and analysis preparation are presented. In the chapter on methodology, the methods used in the research are explained (including tools and used sample). In the chapter results, the outcomes of the research are presented. Finally, in the chapter discussion and conclusion, the results are discussed in the context of three crucial research questions placed at the beginning of this article.

\section{Foundation of reports and analysis creation}

\subsection{Contextualizing for BI skills}

As it was mentioned before, we can observe a large interest in the BI tools that enable organizations to integrate data into their decision-making processes. As the demand for BI increases, the need to teach BI skills also grows. However, it should be noted that BI is a vast and multilayered field with many interconnected components. Some works indicate these elements. Ong with co-workers (Ong et al., 2011) put forward that the BI layers should consist of data source, extract transform load, data warehouse, end-user and metadata. According to Ong et al., the first three layers are related to data management and data operations, while the end-user layer includes tools that display information in different formats to diverse users. These tools are associated with areas such as analytics, delivery visualizations and application consumption. In turn, metadata links the end-user layer to business users to convey the metric context. Todd (Todd, 2018) proposes slightly different layers such as data management, intelligent calculations, delivery mode, consumption device, and business enablement. Todd holds that data management focuses on data source type, data volume, and connections, while intelligent calculation is related to analytical functions used o answer questions. The subsequent layer, the delivery mode, consists of applications connected with visualization and metric delivery, and the consumption device comprehends tools in which visualizations are delivered. Finally, business enablement concerns issues such as training and support. Based on the proposed layers, Todd (Todd, 2018) investigated the skills needed in each of them. Here is the full set of his findings. 
Table 1.

Skills needed in BI layers

\begin{tabular}{|l|l|}
\hline Layer & Skills \\
\hline Data management & $\begin{array}{l}\text { Abilities associated with data wrangling tools: } \\
\text { - how to join disparate data sources, }\end{array}$ \\
& - how to clean data (remove data errors and inconsistencies), \\
& - how to organize data better for analysis, \\
& - how to wrangle structured and unstructured data, \\
& - being aware of best practices in data wrangling.
\end{tabular}

\subsection{Background for reporting and analyzing}

Reporting in project management is one of the ways to communicate with project stakeholders. This is also the first step in business analysis. Although reporting and analysis draw upon the same collected data, according to Dykes (Dykes, 2010), reporting and analysis are very different in terms of their purpose, tasks, outputs, delivery and value. Thus, for this reason, they can be used neither interchangeably nor as synonyms. He indicates that "reporting is the process of organizing data into informational summaries to monitor how different areas of a business are performing" (Dykes, 2010). In other words, reporting is treated as the process of organizing data in documents to monitor business performance. In contrast, "analysis is the process of exploring data and reports to extract meaningful insights, which can be used to better understand and improve business performance" (Dykes, 2010). Thus, analysis is the process of exploring data to draw valuable conclusions that can be used to better understand the business and improve its efficiency. Comparing these two we can notice that reporting processes raw data into more easily digestible information sets and lets us answer the question "what happened?". Meanwhile, analysis allows us to answer the question "why it happened?" The main activities performed during reporting are usually automated. Among them we can indicate: configuring, organizing, formatting and summarizing. During the analysis process we ask business questions, research, interpret, compare, confirm or reject hypotheses (Figure 1). As we can see in Figure 1, the actions related to reporting seem to be less demanding than these linked with analysis. 


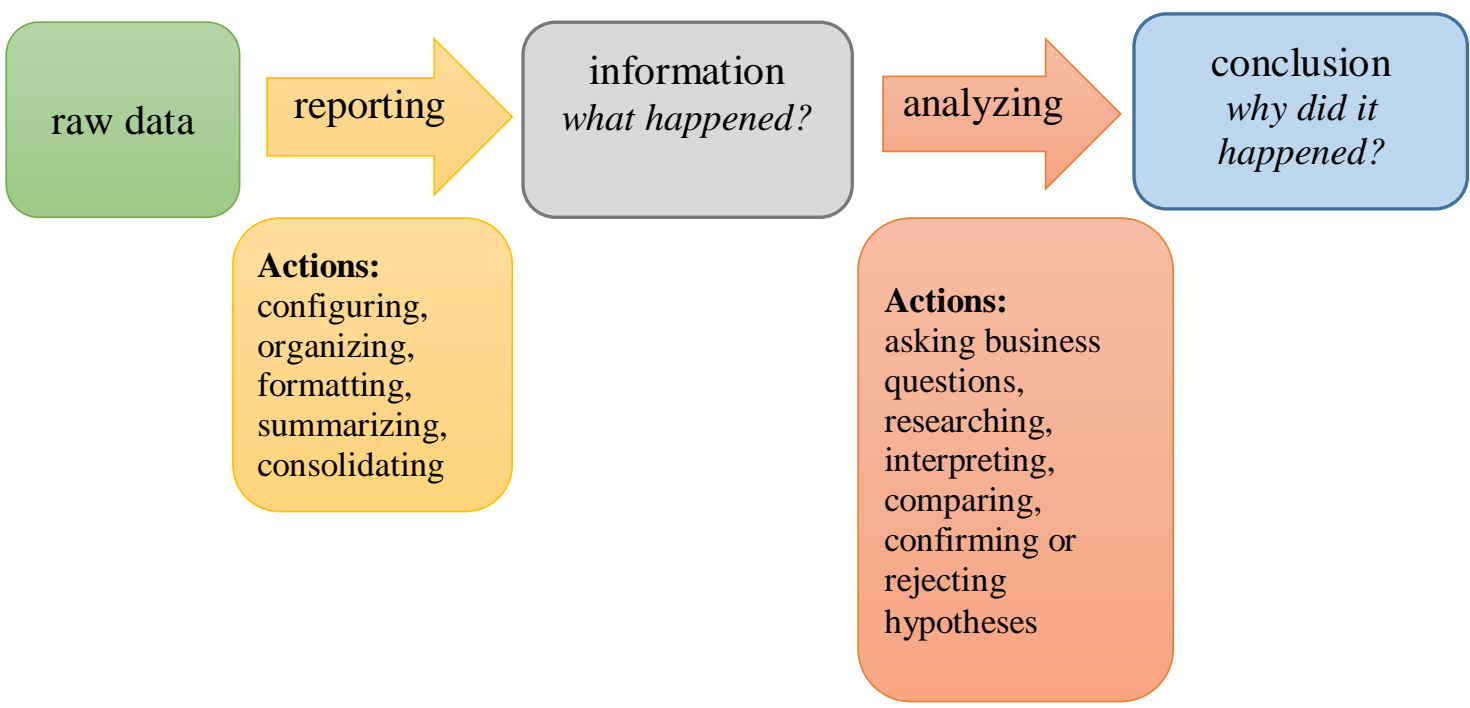

Figure 1. Differences between reporting and analyzing. Source: own study.

As stated previously, reports are often just a starting point for further business analysis. The most common objects on reports are dimensions and metrics. Dimensions represent business concepts, such as tasks in a project, employee, month, and so on. In the terminology of statistics, they are called 'categorical variables'. Putting dimensions on the report provides a context for the data calculations (metrics) that are usually the core of any business reporting. Dimensions serve as labels for metrics values. Metrics represent a business measure or key performance indicator, such as revenue, cost, employee headcount, and so on. Metrics are the calculations performed on data stored in the database. In statistics, they are called 'numerical variables'.

\section{Methodology}

The basic research method used to attain the goal of the article was a participatory observation. In 2018 and 2019, the author of the article participated in a project financed by the European Union. This was a project whose main goal was to modernize university level education. The author's participation was related to taking part in the work of the management team of this project. One of the tasks that the project team had to do, was the creation of reports and analysis. All of these had a financial context and were required by external and internal stakeholders. Both reports and analyses were based on data coming from internal accounting systems. They covered the period of nine months, from October 2018 to June 2019. Data for each month included an average of 440 booked items. The exception was December 5784 items. This data was grouped and summarized to be set to the template of the report and subsequently to the IT system delivered by external stakeholders. The final version of the report imported to that system contained items grouped and summarized by different dimensions. 
Among them there were: number of the project task, number of documents, account number, date of a document, date of payment, name of the cost, category of the cost, and so on.

Following Todd (Todd, 2018), five BI layers were established (data management, intelligent calculations, delivery mode, consumption device, business enablement). Each of these was investigated in terms of operations performed by a business analyst, and in terms of the IT tools used during these operations. On this basis, the set of skills needed for each layer were identified.

\section{Results}

When looking at data management, the investigation revealed the presence of the following skills: joining disparate data sources, cleaning data, and better data organization. IT tools such as internal financial systems and spreadsheets were used within the data management layer. Using the mentioned tools, operations related to data exporting from the internal financial systems into the spreadsheets were used. However, it should be noted that before data exportation, they were filtered and sorted. The person who dealt with these operations was deeply involved in following all financial cash flows in the project. For this reason, she was able to contrive the proper filtering of data and eventually their appropriate export. To account for the fact that the project stakeholder introduced established rules of reporting, the data had to be properly processed and prepared. Primarily, it was necessary to join data containing a dictionary description of financial project categories. Secondly, new dimensions had to be created. To meet both requirements, operations using text functions (e.g. LEFT, RIGHT, REPLACE), search functions (e.g. SEARCH, VLOOKUP), and specific condition testing functions (e.g. IF, IFERROR) were applied. The most useful application in this layer were spreadsheets, especially MS Excel.

With regard to intelligent calculation, the investigation revealed the presence of the following skills: queries design and creation of calculations (metrics) based on statistical functions. The most valuable IT tools were database applications (MS Access), especially in the area of extracting information using queries. The most useful type of queries were these that allowed showing aggregations for different groups of dimensions. The most used aggregation function was summarizing. The choice of database application instead of spreadsheets was determined based on the need to incorporate and show a large number of data derived from the financial system, which had to be summarized and organized following the requirements of the stakeholder. MS Excel was unable to do this; neither pivot tables nor partial totals gave satisfactory results for such a huge amount of data. However, it is worth noticing that some aggregations based on the pivot table in MS Excel were also used in the case of smaller parts of data. They were very useful in finding incorrectly posted costs. 
When looking at delivery mode, the investigation revealed the presence of the skills related to report designing. Thus, reports were created based on dimensions and metrics produced in the data management and the intelligent calculations layers. To account for the fact that the stakeholder delivered the template of the report, the initial version of the report (made in MS Access) was exported to the template and enriched by additional information. The creation and use of macros turned out to be a great facilitation of the work. The main form of data visualization in this template were grids made by using MS Excel.

The most often used operation in the consumption device layer was the adjustment of the report to the system delivered by the stakeholder. The main problems that had to be solved were ones related to the format of imported data.

In the business enablement layer, the investigation revealed the presence of team member mutual training. The project team consisted of people of different competences. There were people with strong competencies in the field of finance and those who had strong abilities in the ground of IT tools. Mutual training allowed to increase the percentage of automatic operations performed during the report creation. The first iteration to create the report used $30 \%$ automatic operations and the last one, $70 \%$. Thanks to this, along with the creation of subsequent reports, the number of operations involving the manual replenishment of the report decreased.

The full set of skills and related operations in all BI layers of the investigated processes can be found in Table 2 .

Table 2.

Skills used in reports and analysis creation

\begin{tabular}{|c|c|c|}
\hline Layer & Skills & Operations performed on data \\
\hline Data management & $\begin{array}{l}\text { joining disparate data sources } \\
\text { cleaning data } \\
\text { better data organization }\end{array}$ & $\begin{array}{l}\text { - } \text { support for files that allow the exchange of data } \\
\text { between applications, } \\
\text { - data sorting and filtering, } \\
\text { - creation of new dimensions based on text } \\
\text { functions, } \\
\text { - assigning dimensions based on search functions. }\end{array}$ \\
\hline $\begin{array}{l}\text { Intelligent } \\
\text { calculations }\end{array}$ & creation of calculations & $\begin{array}{l}\text { - queries creation based on selected dimensions } \\
\text { and derived metrics (summarizing, grouping), } \\
\text { pivot table creation. }\end{array}$ \\
\hline Delivery mode & data visualization & $\begin{array}{l}\text { reports designing based on related dimensions } \\
\text { and metrics derived from obtained queries, } \\
\text { - creation and use of macros, } \\
\text { - reports enrichment with additional labels. }\end{array}$ \\
\hline Consumption device & $\begin{array}{l}\text { adjustment of visualizations } \\
\text { to tools used by end-user to } \\
\text { consume visualizations }\end{array}$ & 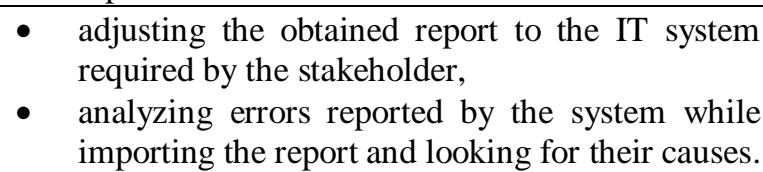 \\
\hline Business enablement & & $\begin{array}{l}\text { - mutual training of team members, } \\
\text { analyzing resources from financial systems to } \\
\text { find additional data to facilitate the automation of } \\
\text { report creation. }\end{array}$ \\
\hline
\end{tabular}




\section{Discussion and conclusion}

The conducted investigation revealed the presence of all BI layers indicated by Todd (Todd, 2018). It is worth noticing that the data management processes dominated all business analysis processes in terms of time spent on these tasks. Particularly a lot of time was taken by processes related to data wrangling. This condition is also described by Todd (Todd, 2018) in his research. Spending hours with data wrangling processes was related to the necessity of joining disparate data sources coming from internal financial systems and files containing the description of invoices, payrolls, employees and project categories. The project team did not use the special tools dedicated to data wrangling mentioned by Green (Green, 2010), but a tool dedicated to data visualization was applied where the module of data wrangling was implemented. The main tool used in the data management layer was MS Excel with sets of functions in terms of search, conditioning and text handling. It can, therefore, be concluded, as Chung (Chung, 2019) did, that MS Excel has high usability in terms of data management. When it comes to intelligent calculation, MS Access was the most used tool. The reason for this was the fact that no other reporting tool was available to the project management team. However, this did not delay the work on reports because the capabilities of MS Access in the range of generating queries and data aggregation fulfilled needs in terms of report preparation.

In the case of the studied project, the predominance of time spent on reporting than on analysis processes was noticed. The evidence of this dominance is that activities such as building, configuring, consolidating, organizing, formatting, and summarizing were more frequently undertaken. All these actions, according to Dykes (Dykes, 2010), can be recognized as parts of the reporting processes. The reason for the predominance of reporting processes can be explained by the project stakeholders requirements regarding high frequency of reports.

To account for the high use of MS Excel and MS Access, the investigation revealed the sets of skills needed in all analyzed BI layers. In the data management layer, the most useful skills are joining disparate data sources, cleaning data and better data organization. The MS Excel functions supporting these processes are search functions, specific condition testing functions and text handling functions. In the intelligent calculation layer, the most important skills are the creation of calculation. A useful application in this layer is MS Access. The MS Access operations supporting the creation of calculations are queries construction based on selected dimensions and derived metrics (summarizing, grouping). In terms of MS Excel, the most useful is the pivot table. In the delivery mode layer, the creation and use of macros turned out to be great facilitation of work. In the consumption device and business enablement layers, the most important skills are the mutual training of team members and abilities enabling analysis of errors. 


\section{References}

1. Abbott, D. (2014). Applied predictive analytics: Principles and techniques for the professional data analyst. John Wiley \& Sons.

2. Al-Sakran, H.O. (2014). Analysis of Business Analytics Curricula and Job Demand in Saudi Arabia. Life Science Journal, 11:8, 918-926.

3. Bobriakov, I. (2018). Comparative Analysis of Top 6 BI and Data Visualization Tools in 2018. Retrieved from https://www.kdnuggets.com/2018/02/comparative-analysis-top-6-bidata-visualization-tools-2018.html.

4. Chiang, R.H.L., Goes, P., and Stohr, E.A. (2012). Business Intelligence and Analytics Education, and Program Development: A Unique Opportunity for the Information Systems Discipline. ACM Transactions Management Information Systems, 3:3, 12.

5. Chung, L. (2019). Microsoft Access versus Microsoft Excel for Data Analysis and Reporting. Retrieved from http://www.fmsinc.com/MicrosoftAccess/DataAnalysis/versusexcel.html, 2019.06.20.

6. Davenport, T.H., and Patil, D.J. (2012). Data Scientist: The Sexiest Job of the 21 st Century. Harvard Business Review, 90, 70-76.

7. Davis, G.A., Woratschek, C.R. (2015). Evaluating Business Intelligence/Business Analytics Software for Use in the Information Systems Curriculum. Information Systems Education Journal, (13:1), 23-29.

8. Dykes, B. (2010). Reporting vs. Analysis: What's the Difference? Retrieved from https://theblog.adobe.com/reporting-vs-analysis-whats-the-difference/, 2010.10.19.

9. Edgington, T.M. (2011). Introducing Text Analytics as a Graduate Business School Course. Journal of Information Technology Education: Innovations in Practice, 10, 207-234.

10. Gorman, M.F., and Klimberg, R.K. (2014). Benchmarking Academic Programs in Business Analytics. Interfaces, 44:3, 329-341.

11. Green, A. (2010). Seven Free Data Wrangling Tools. Retrieved from https://www.varonis.com/blog/free-data-wrangling-tools/, 2010.10.30.

12. Hosack, B., and Sagers, G. (2015). Applied Doctorate in IT: A Case for Designing Data Science Graduate Programs. Journal of the Midwest Association for Information Systems, $1: 1,61-68$.

13. Lee, Y., Madnick, S., Wang, R., Wang, F., and Zhang, H. (2014). A Cubic Framework for the Chief Data Officer: Succeeding in a World of Big Data. MIS Quarterly Executive, $13: 1,1-13$.

14. Li, L., Zhang, C., and Zheng, G. (2014). Identifying Important Skill Sets to Support Healthcare Data Processing and Analytics: An Empirical Examination of Perceptions from HIT Practitioners. Proceeding of Twentieth Americas Conference on Information Systems. Savannah, Georgia. 
15. Mamonov, S., Misra, R., Jain, R. (2015). Business Analytics in Practice and in Education: A Competency-based Perspective. Information Systems Education Journal, 13:1, 4-13.

16. Negash, S. (2004). Business intelligence. Communications of the Association for Information Systems, 13, 177-195.

17. Ong, L., Siew, P.H., \& Wong, S.F. (2011). A five-layered business intelligence architecture. IBIMA Publishing, 695619. doi:10.5171/2011.695619.

18. Pomykalski, J.J. (2014). Teaching Business Intelligence through Case Studies. Proceedings of the Information Systems Educators Conference. Baltimore, Maryland USA.

19. Presthus, W., and Bygstad, B. (2012). Business Intelligence in College: A Teaching Case with Real Life Puzzles. Journal of Information Technology Education: Innovations in Practice, 11, 121-137.

20. Sircar, S. (2009). Business Intelligence in the Business Curriculum. Communications of the Association for Information Systems, 24, 289-302.

21. Todd, J. (2017). Data-Driven Decisions: Business Intelligence (BI) Training Skills. All Theses And Dissertations, 127. Retrieved from http://dune.une.edu/theses/127.

22. Top Business Intelligence Trends 2019: What 2,679 BI Professionals Really Think. Retrieved from https://bi-survey.com/top-business-intelligence-trends.

23. Van der Aalst, W.M. (2014). Data Scientist: The Engineer of the Future. Proceedings of the I-ESA Conferences, Enterprise Interoperability VI. Springer International Publishing, 13-26.

24. Wang, Y. (2015). Business Intelligence and Analytics Education: Hermeneutic Literature Review and Future Directions in IS Education (May 6, 2015). Proceeding of Twenty-First Americas Conference on Information Systems (AMCIS), Puerto Rico. Available at https://ssrn.com/abstract=2603365.

25. Watson, H.J. (2009). Tutorial: Business intelligence - past, present, and future. Communications of the Association for Information Systems, 25, 487-510.

26. Wilder, C.R., \& Ozgur, C.O. (2015). Business Analytics Curriculum for Undergraduate Majors. INFORMS Transactions on Education, 15:2, 180-187.

27. Wixom, B., Ariyachandra, T., Douglas, D., Goul, M., Gupta, B., Lyer, L., Kulkarni, U., Mooney, J.G., Phillips-Wren, G., and Turetken, O. (2014). The Current State of Business Intelligence in Academia: The Arrival of Big Data. Communications of the Association for information Systems, 34, 1-13. 